\title{
O PAPEL DO CONTADOR NO E-COMMERCE NOS DIAS ATUAIS
}

\section{ARTIGO ORIGINAL}

SILVA, Raiane Lima da ${ }^{1}$, ROBERTO, José Carlos Alves², SERRA, Meg Rocha da Cunha $^{3}$, LOPES, Nelânia Ferreira ${ }^{4}$

SILVA, Raiane Lima da. Et al. O papel do contador no e-commerce nos dias atuais. Revista Científica Multidisciplinar Núcleo do Conhecimento. Ano. 06, Ed. 10, Vol. 03, pp. 89-104. Outubro 2021. ISSN: 2448-0959, Link de acesso: https://www.nucleodoconhecimento.com.br/contabilidade/contador-no-e-commerce, DOI: 10.32749/nucleodoconhecimento.com.br/contabilidade/contador-no-ecommerce

\section{RESUMO}

O mercado vem evoluindo e no comércio não seria diferente. A compra virtual passou de uma opção para uma evolução, pois está progressivamente em expansão, a possibilidade de comprar sem sair de casa vem conquistando muitos consumidores e atraindo muitos novos empreendedores. As pessoas buscam agilidade e praticidade, seja por falta de tempo, trânsito ou por descontos atraentes. O presente Artigo tem como pergunta principal: qual o papel do contador no $E$ commerce atualmente? E quanto aos objetivos: visa demonstrar o papel do contador no E-commerce e a importância de uma empresa trabalhar legalizada, tendo o contador como ferramenta estratégica para o planejamento e organização de uma empresa. A pesquisa é bibliográfica e documental com base nos assuntos já existentes sobre E-commerce e sobre a importância de se ter um contador, o tipo de

\footnotetext{
${ }^{1}$ Graduanda do curso de Ciências Contábeis.

${ }^{2}$ Orientador. Mestre em Engenharia de produção. Especialista Logística empresarial. Graduado em Administração com Ênfase em Marketing.

${ }^{3}$ Orientadora. Mestra em Engenharia de Processos Industriais pela UFPA, especialista em Controladoria e Auditoria Contábil pelo Ciesa, Graduada em Ciências Contábeis pelo Centro Universitário do Norte. Graduada em Ciências Econômicas pelo Centro Universitário do Norte.

${ }^{4}$ Orientadora. Especialista em Auditoria Contábil, Financeira e Tributaria e Graduada em Ciências Contábeis.
}

RC: 98771

Disponível em: https://www.nucleodoconhecimento.com.br/contabilidade/contadorno-e-commerce 
abordagem utilizada foi a qualitativa. Portanto, concluímos que é necessário o auxílio de um contador para o processo de abertura de uma empresa, quanto seu papel no planejamento, pois a imagem de que o contador é somente para calcular impostos é distorcida e ilusória, o papel do contador é muito mais que isso.

Palavras-chaves: E-commerce, o Papel do Contador, Planejamento.

\section{INTRODUÇÃO}

O comércio eletrônico se tornou uma popular opção de compra e vem crescendo sucessivamente, o modelo de compra online atrai todo tipo de público, o que ocorre por conta da facilidade de comprar diretamente de seu lar. A principal vantagem do crescimento do comércio eletrônico para os empreendedores que estão inseridos nesse meio, é a possibilidade de realizar vendas em qualquer horário, não apenas em determinado horário assim como ocorre na maioria dos comércios físicos.

Com isso, a internet passou a ser aliada do empreendedor e abriu fronteiras para o comércio, a expansão do mercado é a evolução dos negócios. Muitos empreendedores iniciam no comércio virtual de forma remota e sem o conhecimento necessário para se manter uma empresa, sendo ela pequena ou grande, é preciso trabalhar de forma legalizada e ter um CNPJ.

O papel do contador é essencial para a parte financeira e administrativa e com passar dos anos, ele passou a ser mais estratégico e tático, possibilitando projeções para o futuro da empresa, por ser possível acompanhar o desenvolvimento através de informações das demonstrações contábeis para a tomada de decisões.

A metodologia de pesquisa usada neste artigo foi a exploratória, com estudo bibliográfico e documental, com base em pesquisas em livros decorrente de apreciações dos autores referente ao assunto abordado, o tipo de abordagem utilizada foi a qualitativa. Salienta-se a intenção de responder à pergunta da pesquisa: qual o papel do contador no E-commerce atualmente? Pontuando os 
motivos de se trabalhar regularizado com autonomia do negócio, com a cooperação de um contador tendo como objetivo o crescimento da empresa.

Dessa forma, o objetivo geral desse artigo foi ressaltar o papel do contador para o $E$ commerce, principalmente na legalização da empresa e sua importância no direcionamento do planejamento de uma empresa para seu crescimento no mundo dos negócios.

A relevância do estudo tem a importância de apresentar as razões das empresas virtuais trabalharem legalizadas, tendo em vista também o bom planejamento que uma empresa necessita.

\section{FUNDAMENTAÇÃO TEÓRICA}

Refere-se ao trabalho em si, onde será apresentado o assunto desenvolvido e suas concepções em relação a determinado tema. É a parte referente ao desenvolvimento, onde o autor vai relacionar teorias de outros autores e fazer afirmações com base em pesquisas relacionadas ao tema mencionado, para que seja exposta com o propósito do seu trabalho (LIBÓRIO; TERRA, 2015).

\subsection{E-COMMERCE NO BRASIL}

E-commerce no Brasil se deu juntamente com o avanço da internet nos anos $90 \mathrm{e}$ desde então esse comércio vem crescendo e avançando cada vez mais, porém começou a engrenar e ter sua situação contabilizada nos anos 2000 e a partir daí é que teve uma noção do seu faturamento e desde lá só cresce. Uma das pioneiras no Brasil é a Magazine Luiza que ainda hoje é uma potência nesse ramo.

Nos dias atuais é impossível viver sem internet. Cada dia mais, as pessoas estão dependentes, seja usando-a para serviços, falar com outras pessoas ao redor do mundo através das redes sociais, banco e com compras (OLIVEIRO; DEGHI, 2015). 
E-commerce ou Comércio eletrônico é também uma maneira mais fácil de montar seu negócio, o que facilita e muito para os pequenos empreendedores que querem entrar no mercado. O comércio eletrônico pode ser definido como uma operação comercial usando objetos eletrônicos como troca de informações, comprar a distância e não precisa sair de casa, basta comprar pelo computador ou outro meio com internet (SALVADOR, 2013).

A busca por praticidade é o que mais motiva a busca constante por produtos ou serviços no mundo inteiro, como basta ter acesso à internet, isso já é o suficiente para finalizar o seu pedido.

A fase eletrônica vai mudar completamente a humanidade, e será a maior revolução que já existiu depois da Revolução Industrial. Com a dominação do papel da tecnologia e estará acessível a todos (RIBEIRO, 2011).

O ano de 2020 colaborou para a expansão do comercio eletrônico e cooperou para o crescimento dos pedidos e compras virtuais. A solução adotada pelas empresas que tiveram de fechar as portas foi migrar de forma compulsória para o comércio virtual, se reinventando por meio do E-commerce.

A opção de comprar de qualquer lugar e a qualquer momento é um aliciante que vem encantando muitos clientes, visando isso muitos empresários do setor de lojas físicas ingressaram para o comércio eletrônico. É quase que impossível de encontrar uma pessoa que nunca tenha feito uma compra pela internet, já que grande parte dos contratempos de se efetuar uma compra através da internet foram caindo no decorrer dos anos (RODRIGUES, 2018). Surgem novos empreendedores que optam por iniciar seu negócio como loja virtual, pois uma das vantagens é o baixo custo que o E-commerce oferece e pela sua funcionalidade. A opção de gerir uma empresa virtual atualmente é sinônimo de ascensão ao mundo do comércio que está em constante evolução. 


\subsection{EMPRESA FÍSICA X LOJA VIRTUAL}

Um empresário precisaria de um valor alto para iniciar a investir em um ponto físico, e muitas vezes requer tempo para organizar uma loja física para o funcionamento. Uma empresa física tem custos como aluguel de ponto comercial, luz, internet, IPTU, funcionários, dentre outras coisas. Enquanto o E-commerce inicialmente não precisaria disso tudo, o que torna a vida de quem inicia muito mais fácil, sem preocupação com altos investimentos e com o operacional que uma empresa física demanda. Com a correria do dia a dia esse ramo é um atrativo para quem quer facilidade, por exemplo: depois de um dia cansativo no trabalho ou para quem deseja evitar trânsito, fugir de filas e estacionamentos, ou seja, de toda logística que é sair de casa. A experiência de compra via internet ganha cada vez mais destaque e isso vem crescendo a cada ano, as empresas buscam se diferenciar para conquistar mais clientes, já que os compradores podem acessar e fazer comparações instantaneamente (SALVADOR, 2013).

Fazer uma busca na internet por produtos e serviços é sem dúvidas muito relevante, as pessoas podem fazer uma pesquisa ampla sobre determinado produto ou comprar vários produtos ao mesmo tempo, isso tudo é claro, sem sair de casa. Por isso é importante que o produto contenha informações necessárias, isto significa, quanto mais informação melhor, desse jeito evita trocas do produto e reclamações.

Outro ponto relevante também é em relação ao horário, enquanto muitas empresas físicas trabalham com horário comercial, uma loja virtual trabalha 24h por dia de domingo a domingo, ou seja, o empreendedor terá vendas mesmo depois do horário comercial.

Contudo, existem pessoas que preferem de certa forma comprar somente presencialmente alguns produtos como: roupas, perfumes e sapatos. A empresa física conta com os sentidos sensoriais como estimulante para a finalização da compra como por exemplo o toque e a possibilidade de experimentação e de poder 
sair de lá com o produto em mãos, o que causa uma satisfação de não ter que esperar a entrega (RODRIGUES, 2018).

Por esse motivo, empresas investem progressivamente nas estratégias de vendas para conquistar esse público com opções de frete grátis e cupons de descontos, tudo isso é usado como forma de conquistar a confiabilidade dessas pessoas que ainda tem uma certa carência por pontos físicos. Na empresa física o processo de compra é até mais demorado e trabalhoso, pois tem deslocamento, é preciso visitar o local, mas na finalização da compra a pessoa já saí com o produto na hora. Nas compras virtuais, leva minutos para a finalização, porém o cliente necessita muitas vezes esperar alguns dias para receber o produto/serviço (SAULLO, 2016)

Com a busca constante por produtos e serviços na era virtual cresce todos os dias, as empresas físicas buscam gradativamente migrar para esse setor do comércio eletrônico. Visando buscar a aprimorar ou manter uma relação de empresa/consumidor, as empresas acabam ingressando para o E-commerce como um atrativo a mais, para cativar o público que quer comodidade e praticidade. $\mathrm{A}$ praticidade é a solução de um dia corrido, de filas e procura por uma vaga de estacionamento, pelo preço da gasolina e de horas parado num engarrafamento de trânsito. A comodidade é o poder comprar sem sair de casa, pesquisar um produto em vários lugares diferentes e ter a certeza que está comprando no lugar certo com todas as vantagens de se comprar virtualmente, sem se locomover para isso.

A empresa física não sairá do mercado, e nem perderá espaço, mas em tempos de avanços e de desenvolvimento ou até mesmo de soluções práticas, o comércio eletrônico tem aberto um leque de possibilidades no mundo. Vender e comprar nunca pareceu tão fácil e vender para o mundo todo a base de internet é fenomenal. As empresas visam expandir-se a todo custo e a todo momento, acompanhar a globalização é fundamental. Por exemplo, a pandemia que isolou muitas pessoas na quarentena e fez o serviço virtual se tornar essencial. 
Muitas empresas tiveram que se reinventar, trabalhar remotamente e com delivery para não perderem clientes, ampliaram os canais de comunicação e deram opções de comprar virtualmente foi a solução para muitas empresas não quebrarem. Independente do negócio ser pequeno, médio ou grande é preciso que todos estejam a bordo. Ainda que tenham o melhor plano para execução todos precisam estar envolvidos se não será em vão (LAWRENCE, 2019).

A constante evolução é o princípio para novas possibilidades e variedades, ter a opção de escolher se quer comprar de casa ou de se deslocar até o local é a vez do momento e oferecer isso ao cliente é legal. A vida de um empreendedor ou empresário é uma constante corrida contra o tempo e seu segredo é a maneira de se reinventar sem perder a sua essência. Onde as mudanças se desenvolvem cada vez mais, fazendo parte do dia a dia (FILHO, 2019).

\subsection{O PAPEL DO CONTADOR NO E-COMMERCE}

Abrir uma empresa embora aparenta ser coisa fácil, muitas vezes não é. Dependendo do tipo de empresa é preciso uma documentação e é aí que entra o papel do contador, auxiliando na abertura da empresa, fazendo assim seu registro perante os órgãos responsáveis pela fiscalização. Da mesma forma que a Pessoa Física precisa do CPF à Pessoa Jurídica precisa do CNPJ (Cadastro Nacional de Pessoa Jurídica), com ele é possível sair da informalidade e ganhar alguns benefícios que uma empresa jurídica tem, como por exemplos: benefícios perante os bancos, permissão para emissão de notas fiscais e previdência social.

A contabilidade tem dois objetivos e funções: econômica e administrativa, buscando prover informações para o controle do planejamento das operações, informações de caráter financeiro, patrimonial e econômico (PORTUGAL et al., 2015).

Muitas pessoas acreditam que por trabalharem na internet estão isentos de fiscalização, mesmo que a empresa seja virtual ela precisa do seu registro para trabalhar legalizado sem preocupações com o fisco. Ter um CNPJ garante direitos e 
deveres e é importante ter um. Deve-se estabelecer a razão social, nome fantasia, emissão de alvará de funcionamento, cadastro de previdência social, emissão de inscrição estadual e municipal, planejamento tributário, porte da empresa, escolhendo qual o melhor regime que se enquadre na empresa e analisar suas vantagens e desvantagens, por isso é importante o auxílio do contador.

O empresário deve procurar sobreviver no dia a dia, pois a luta é constante e para isso deve escolher um planejamento tributário eficaz, para garantir a diminuição de pagamentos de tributos. Com a ajuda de um profissional habilitado com experiência na função e respeitando as leis (TODA, 2018).

Por esse motivo, direcionar o empresário para o melhor planejamento, com planos de contas, diminuir gastos, pagar os tributos de forma certa e na data exata é importante. Definir estratégias financeiras e elevar as receitas também são algumas funções do contador, manter uma relação com esse profissional é fundamental para juntos construírem uma empresa de sucesso. Quem não é do ramo não tem noção da pressão que é trabalhar com prazos, visando cumprir todas as obrigações como: fechamento de balanços e apurando impostos. Para ter uma base é preciso verificar o calendário de obrigações que uma empresa tem e ter a noção da encrenca que é (RINCAWESKI, 2014).

A imagem de que contador é somente para calcular Imposto de Renda é errada, a visão que muitos pensam que ele trabalhe somente com isso também é. O papel do contador passou de um simples profissional de calcular impostos, a de um consultor, ele é responsável muitas vezes por orientar o melhor caminho que uma empresa possa seguir, pois manter uma empresa sem ajuda de um profissional capacitado não é fácil, saber onde está errando ou deixando de ganhar lucros é o que leva muitas empresas a quebrarem. Outra função essencial é sua assessoria em relação ao setor fiscal e tributária, pois dada a dificuldade na nossa legislação fiscal é até difícil se manter sem um direcionamento correto. 
Muitos acreditam que Contador é coisa de empresa grande, o que é outro erro, contador é para qualquer tipo de empresa, seja pequenas ou grandes empresas, para aqueles que iniciam então nem se fale. Iniciar de forma certa e legalizada é um ponto fundamental, buscar este profissional para isso é necessário. A contabilidade é um serviço obrigatório de toda empresa, devendo prestar contas perante os órgãos de fiscalização.

O papel do contador é de extrema necessidade dentro das organizações-empresas, pois é preciso atender exigências e transmitir informações aos setores responsáveis pelas cobranças legais. Fazendo-se necessário elaborar os livros e demonstrativos e relatórios que possam ajudar na tomada de decisão de uma empresa (MUTTI, 2019).

O contador consegue através do Balanço Patrimonial e Demonstrações de Resultados, passar informações como o índice de endividamento da empresa, a sua capacidade de liquidez para efetuar pagamentos, e entre outros índices financeiros. Com base nesse levantamento é preciso fazer sempre uma comparação com o ano anterior para analisar seus pontos fortes e fracos.

Por mais que o contador propicia um modelo de planejamento que é viável para determinada situação ou objetivo, é de responsabilidade do empresário as tomadas de decisões. O contador está ali somente para auxiliar a melhor opção é gerar informações necessárias, mas a decisão final sempre será do empresário. O relacionamento do contador com o empresário se faz necessário para as tomadas de decisões e que seja de forma clara e objetiva para desenvolver a melhor estratégia para gerir a empresa.

As pequenas empresas não devem pensar que ter um contador é um gasto, imagine como um investimento, um parceiro que conduz ao sucesso. Lembre-se que nem toda empresa começou grande, mas com as metas e o planejamento certo tem tudo para conquistar o êxito e aumentar os ativos. Metas é a definição do que a pessoa quer realizar e fazer um planejamento para alcançar o seu objetivo, por mais que 
muitos tenham objetivos, nem todo mundo consegue alcançá-los (LAWRENCE, 2019).

O contador é um aliado fundamental para o desenvolvimento de uma empresa, com base nos seus relatórios é possível definir as tomadas de decisões e de proporcionar as linhas para alcançar um determinado objetivo, seja ele de curto ou longo prazo.

A grande maioria das empresas acredita que o contador se faz necessário somente para calcular o IRPJ e CSLL, outro grande erro. O contador é capaz de dar soluções e de direcionar da melhor forma como prosseguir e evitar tropeços financeiros. O papel do contador como estratégia e auxílio é sempre a melhor opção para as pequenas e grandes empresas.

\subsection{AS VANTAGENS DE AS EMPRESAS FÍSICAS INVESTIREM NO E-COMMERCE}

A importância das empresas em inovar é fundamental, com o avanço da tecnologia - E-commerce é um atrativo bem interessante. Como muitas pessoas procuram diversidade, agilidade e facilidade atualmente, o comércio eletrônico é uma opção quase como uma estratégia para chamar ou ganhar clientes, e muitas empresas começaram a observar essa necessidade de facilidade que muitos procuram. Uma empresa existe para atender pessoas e deve acompanhar a evolução dos seus consumidores sem perder sua essência e está aberta para mudanças e adaptações na sociedade (FILHO, 2019).

Com o avanço da internet e com os surgimentos de novas tecnologias a tendência é só aumentar e com a geração que necessita de praticidade para resolver tudo com um click, com o comércio não seria diferente. O E-commerce para empresas físicas sem dúvidas é uma estratégia comercial e de marketing, investir nesse setor é um passo importante. O consumo via internet se dá principalmente pelo fato de preços mais baixos, essa percepção é o resultado do crescimento desse consumo. Muitos 
fazem uma comparação de preços e identificam o valor de determinado produto através de informações colhidas, para que assim ele realize sua compra (SALVADOR, 2013).

A importância de cativar cada dia mais os clientes é um dos recursos que a maioria das empresas visam, e com isso é sempre uma opção usar dos meios atuais o comércio eletrônico como solução. É preciso ser competitivo, pois as empresas que estão iniciando no mundo virtual estão buscando a todo instante levar seus produtos através de anúncios aos consumidores e as pessoas buscam segurança na hora da compra e passar isso é exatamente o que as empresas estão buscando, e por isso investir em marketing na hora das vendas é a cereja do bolo. Fascinar e tornar a experiência de compra única é o ponto de acerto de muitas empresas e estar aí, o motivo crescente das estratégias de marketing que vem progredindo diariamente. Ao se basear em experiências de outras pessoas, ter uma visão e opinião de terceiros é um dos princípios que leva algumas pessoas a comprarem ou não comprarem em determinado lugar, são experiências que fazem daquele negócio o sucesso ou fracasso. Independentemente de qual for o tipo de loja ou gênero de produtos oferecidos e vendidos, um bom atendimento é essencial e a referência de excelência nesse ponto é o sucesso dos negócios, aumento nas vendas e dos lucros (SAULLO, 2016).

A imigração para o sistema de comércio virtual se dá por motivos de expansão do comércio e pela competitividade do mercado, ou por evoluções que são atribuídas frequentemente no mundo. O comércio está em processo de elevação e é importante acompanhá-lo. Por esse motivo as empresas físicas se veem obrigadas a estar um passo a frente.

Nos dias atuais, a maioria dos negócios são digitais. Para muitas empresas essa transição foi e ainda é um grande desafio. Algumas foram pioneiras, outras quase caíram e outras não resistiram (RIBEIRO, 2011). 
As vantagens que uma empresa física tem em investir no E-commerce é na distinção de vendas e na agilidade, no custo-benefício que se tem com um operacional de um ponto comercial, ou seja, também na possibilidade de ter a chance de conhecer melhor seus clientes e de alcançar fronteiras além do comércio físico para aumentar os lucros da empresa são algumas delas.

\subsection{AS VANTAGENS DO E-COMMERCE}

A parte financeira por si só já é uma vantagem, pois não necessitam de altos investimentos, inicialmente ter um estoque e internet é o suficiente. Muitos empreendedores iniciam trabalhando de forma remota por falta de dinheiro ou porque esse é o ramo em que muitas empresas iniciantes se identificam. A estratégia de marketing dessas empresas é essencial para chamar os clientes, visando um espaço nesse meio competitivo que o E-commerce se tornou. $O$ comércio eletrônico se tornou uma potência comercial que cresce cada vez mais, atraindo novos investidores e elevando o mercado. A vantagem de trabalhar com a internet é não precisar se preocupar com o operacional que uma empresa física requer e com um fluxo de funcionários. Correr contra o tempo é basicamente o que o empresário faz constantemente e aprender se adaptar sem perder seus fundamentos é uma resiliência mesmo tendo qualidades aparentes (FILHO, 2019).

Apesar de grandes empresas do E-commerce terem um patamar parecido com uma loja física, muitos não têm essa opção e nem precisam de tanto para começar. Como todo negócio, esse ramo tem seu segredo e é preciso zelar por todos os seus clientes, durante sua navegação no site e direcioná-los ao produto e se preocupar com as informações necessárias e tentar de forma agradável mostrar a satisfação e experiências de outros compradores daquele produto (SAULLO, 2016).

Mesmo que a parte financeira seja um dos principais motivos para abertura de um E commerce, isso não significa que a empresa é menos importante que qualquer outra. Tem deveres e tem que ter foco, pois esse setor é muito competitivo. $O$ marketing e a comunicação são indispensáveis para atrair os clientes. A educação é 
o básico para qualquer negócio de sucesso, o bom atendimento é um dos pontos importantes, a qualidade e o preço também. As pessoas buscam segurança e muitas empresas oferecem isso.

Ser um empreendedor bom é ter uma visão ampliada e buscar ir sempre mais longe procurando informações para obter conhecimento, equilíbrio e experiência para o negócio (FILHO, 2019).

O hábito de compra vem crescendo constantemente e aos poucos as pessoas vão se tornando consumidores pela funcionalidade que o comércio eletrônico apresenta, mas existe também o grupo de pessoas inseguras, pois o comércio virtual traz consigo golpes cada vez mais comuns. Muitos buscam pessoas próximas que tiveram algum tipo de experiência na compra on-line e que finalizaram suas compras tendo êxito na entrega do seu produto, por isso as pessoas procuram, contato com experiências de terceiros ou familiares.

As empresas visam transmitir uma margem de segurança e confiabilidade aos seus clientes, pois querendo ou não, os golpes estão aí e fazem parte de qualquer negócio. Mesmo com histórias negativas e experiências frustradas na internet não se pode negar o seu desenvolvimento. A internet apresenta a facilidade e um comodismo para algumas pessoas e expansão para algumas empresas, por isso a margem de confiança é indispensável. Com tudo isso, o comércio eletrônico busca uma relação de empresa e cliente, através dessa necessidade é possível ter um feedback autêntico de determinado produto ou serviços, sejam positivos ou negativos.

Uma das formas que as empresas estão buscando atrair seus clientes é manter uma relação nas redes sociais e criando perfil para fortalecer essa relação, são essas ferramentas que possibilitam às empresas a conhecerem a preferência das pessoas. A interação que as mídias sociais oferecem é a base de informações que as empresas buscam para monitorar seus consumidores. 
A expectativa que o mundo virtual nos apresenta de fazer tudo de qualquer lugar é fantástica, comprar um produto do outro lado do mundo sem sair de casa é excepcional. Esse comércio veio para agregar e transformar o comércio em geral. Não pense que por ser na internet não tenha concorrência, aí que você se engana, pois, a concorrência está em todo lugar e nesse ramo não seria diferente. As estratégias de vendas e marketing gritam a todo instante, conquistar e trazer cada vez mais o público dos incertos é fundamental. As empresas visam observar as necessidades e desejos dos seus consumidores, a proposta de frete grátis é o que ganha muitos clientes, sem contar a possibilidade de descontos incríveis que a internet oferece.

Quando uma pessoa tem a certeza de que pessoas próximas estão comprando e se satisfazendo na era virtual, as pessoas ficam mais solicitas a entrarem e testarem também. O fato de comprar e não chegar é o medo de muitas pessoas e pensando nessa insegurança é que muitas empresas buscam se blindar disso tudo. Mesmo com tudo isso, é possível notar o crescimento das compras on-line e a evolução do mercado digital, a facilidade que a nova geração procura, a praticidade é certamente o princípio para a nova era.

\section{MATERIAIS E MÉTODOS}

Metodologia é o estudo dos métodos, ou seja, quais as formas necessárias para o desenvolvimento daquele projeto ou a via para a execução. Definir qual o método para se atingir um objetivo é importante e definir o meio para se chegar a algum lugar. Segundo Zanella (2013) a metodologia visa estudar grupos de normas para determinado trabalho científico, ou seja, significa estudo de método, e é utilizada no meio acadêmico de modo como uma exposição para um projeto em si.

Dessa maneira, este trabalho visa aproveitar as ferramentas da contabilidade para explorar métodos que facilitam a acompanhar e organizar a trajetória de uma empresa e sua vida financeira. 


\subsection{PROCEDIMENTOS METODOLÓGICOS}

Quando se trata de procedimentos metodológicos várias dúvidas são pertinentes. Ocorrem porque são elementos bastante parecidos. E cada um deles tem seu objetivo diferente, mas, todos são continentes.

Existe uma diferença entre a metodologia e os procedimentos metodológicos, onde a metodologia é um método que estuda os caminhos para o conhecimento, e os procedimentos metodológicos são todas as técnicas que serão abordadas.

\subsection{QUANTO À NATUREZA}

Dependendo do tipo de pesquisa se é básica ou aplicada e o que determina a finalidade da pesquisa, ou seja, qual o objetivo do projeto e o que será apresentado, novos conhecimentos ou aplicações práticas. O método científico é um ponto de vista sobre homem, natureza e conhecimento, que é usado como base para um conjunto de regras de ação, de procedimentos, determinado para se construir o projeto científico (SILVA, 2015).

A natureza utilizada no projeto foi a básica, a fim de apresentar informações sobre a importância de se ter um contador no E-commerce, visando a utilização das ferramentas da contabilidade para os processos de planejamento de uma empresa virtual.

\subsection{QUANTO AOS FINS}

A pesquisa pode ser classificada em três principais categorias: exploratória, descritiva e explicativa.

Dessa forma, o tipo de pesquisa escolhida para este trabalho é a exploratória, pois ela procura estudar e entender um problema, visando esclarecer e transmitir informações para solucionar as dúvidas existentes. É um conjunto de atividades organizadas e razoáveis que permite alcançar um objetivo de forma segura, através

RC: 98771

Disponível em: https://www.nucleodoconhecimento.com.br/contabilidade/contadorno-e-commerce 
de conhecimentos válidos e autênticos. Planejando o melhor caminho para seguir (LAKATOS; MARCONI, 2003).

A pesquisa exploratória é bastante flexível tendo a possibilidade de explorar o assunto adquirir uma familiaridade com o assunto proposto, fornecendo as respostas das perguntas desenvolvidas durante o trabalho.

\subsection{QUANTO AOS MEIOS}

É quais os procedimentos que pretendem ser usados para buscar as respostas, ou seja, instrumento de coleta de informações para chegar a uma conclusão do trabalho. É fundamental que o leitor saiba qual tipo de pesquisa será abordada, o seu conceito, justificativa de escolha daquela abordagem e sua solução com base na pesquisa oferecida (VERGARA, 2016).

Com base nos tipos de meios para realizar um projeto, os procedimentos escolhidos foram estudo bibliográfico e documental.

\section{CONSIDERAÇÕES FINAIS}

$O$ presente artigo teve como objetivo apresentar o papel do contador para $\circ E$ commerce e a importância do direcionamento desse profissional para a abertura de uma empresa e o seu planejamento. Considerando que a função do contador é mais que calcular impostos, esse profissional vem se tornando cada vez mais um aliado estratégico para o desenvolvimento de uma empresa.

Através da pesquisa apontou-se o quanto é fundamental o papel do contador para o comércio eletrônico, e o quanto é importante as suas atribuições para uma empresa segura e legalizada que garante benefícios como a previdência social, CNPJ regular e uma boa imagem perante o mercado com seus fornecedores.

Compreende-se que muitas empresas virtuais pensam que por trabalharem na internet, não é preciso de regularização e nem pagar impostos. Por mais que 
trabalhem de forma remota é necessário contar com o auxílio de um contador para o seu crescimento e progresso, pois com base nas suas análises é possível acompanhar o desenvolvimento e projetar a empresa para ações futuras.

Muitos empreendedores não buscam ajuda de um profissional por pensarem que empresas pequenas e virtuais não precisam de contador, e acabam trabalhando na informalidade e ficam expostos a fiscalização e até mesmo multas.

Portanto, fica evidente que o Papel do Contador se faz necessário para uma empresa E-commerce que busca seu desenvolvimento e o desdobramento no mundo dos negócios. Começar de forma certa já é um primeiro passo, procurar a redução na carga tributária é outra opção, por isso é importante ter um planejamento estratégico de um contador, a confiabilidade no serviço desse profissional é essencial.

\section{REFERÊNCIAS}

FILHO, D. G. A culpa é do meu contador: como transformar essa relação numa parceria estratégica. 2019.

LAKATOS, E. M.; MARCONI, M. de A. Fundamentos de Metodologia Científica. ed. 05, São Paulo: Atlas, 2003.

LAWRENCE, S. O poder da execução de metas: o guia definitivo para criar metas e o objetivos eficientes que dão resultados. 2019.

LIBÓRIO, D.; TERRA, L. Metodologia científica. Rede Internacional de Universidades Laureate, São Paulo, 2015.

MUTTI, M. A. Contabilidade para empreendedores. Viseu, 2019.

OLIVEIRO, C. A. J.; DEGHI, G. J. E-commerce: princípios para o desenvolvimento e gerenciamento de uma loja virtual. ed. 01, Érica, São Paulo, 2015.

RC: 98771

Disponível em: https://www.nucleodoconhecimento.com.br/contabilidade/contador- 
PORTUGAL, G. T.; et al. Gestão contábil: aspectos introdutórios [recurso eletrônico]. Rio de Janeiro, 2015.

RIBEIRO, N. Gerir na era digital. Prefácio por Rui Pego. Cerci Lisboa, 2011.

RINCAWESKI, I. Contador e empreendedor uma dupla perfeita: conversando sobre o mundo da contabilidade. Blumenau, Santa Catarina, 2014.

RODRIGUES, J. C. E-commerce: conceitos, processos, gestão e monetização. São Paulo, 2018.

SAULLO, E. E-commerce de sucesso: como criar e desenvolver lojas virtuais que vendem. ed. 03, Casa do Escritor, São Paulo, 2016.

SALVADOR, M. Gerente de E-commerce. São Paulo: Ecommerce School, 2013.

SILVA, A. M. Metodologia de pesquisa. ed. 02, Fortaleza Ceará, 2015.

TODA, W. H. Planejamento tributário: fundamentos do direito tributário e o planejamento fiscal e contábil das empresas. 2018.

VERGARA, S. Projetos e relatórios de pesquisa em administração. ed. 16, São Paulo: Atlas, 2016.

ZANELLA, L. C. H. Metodologia de pesquisa. ed. 02, reimp. Florianópolis: Departamento de Ciência da Administração. UFSC, 2013.

Enviado: Setembro, 2021.

Aprovado: Outubro, 2021. 